\title{
Natriuretic peptides in heart failure: where we are, where we are going
}

\author{
Michele Correale $\cdot$ Antonio Totaro • \\ Carmen Greco $\cdot$ Natale Daniele Brunetti • \\ Matteo Di Biase
}

Received: 9 March 2011/Accepted: 19 April 2011/Published online: 1 May 2011

(C) SIMI 2011

We read with great interest the article by Palazzuoli et al [1], which briefly gives a clinical update on natriuretic peptides (NP). The authors describe the role of NP both in heart failure diagnosis and prognosis and in the acute coronary syndrome.

The authors report that repeated evaluation of NP carries prognostic information beyond a single measurement in different clinical settings, and, above all, repeated determinations of NT pro-BNP levels are relevant for the monitoring of disease progression [1]. However, we would remind everything that, in NP-guided outpatient treatment, the interpretation of NP levels must consider the variability of these peptides. Changes in the NP level below 50\% may be in some patients within the range of biological variability and not representative of clinical events. The combination of symptoms, weight gain, and NP levels may be, therefore, probably the best way to make an early diagnosis of an episode of cardiac decompensation [2].

In future perspectives and applications section, we would also add that biomarkers, such NP, might be used to predict a treatment response in settings other than heart failure (e.g., in management of atrial fibrillation, as a predictor of a successful cardioversion) [3] and that NP concentrations may be helpful in preoperative risk stratification (both cardiac and non cardiac surgery) [4].

Conflict of interest None.

\section{References}

1. Palazzuoli A, Antonelli G, Quatrini I, Nuti R (2011) Natriuretic peptides in heart failure: where we are, where we are going. Intern Emerg Med 6(1):63-68

2. Maisel A, Mueller C, Kirkwood AJ et al (2008) State of the art: using natriuretic peptide levels in clinical practice. Eur J Heart Fail 10:824-839

3. Marsiliani D, Buccelletti F, Carroccia A et al (2010) Natriuretic peptides and atrial fibrillation. Eur Rev Med Pharmacol Sci 14(10):855-860

4. LuratiBuse GA, Koller MT, Burkhart C, Seeberger MD, Filipovic M (2011) The predictive value of preoperative natriuretic peptide concentrations in adults undergoing surgery: a systematic review and meta-analysis. Anesth Analg (Epub ahead of print)

\footnotetext{
M. Correale $(\varangle) \cdot$ A. Totaro · C. Greco ·

N. D. Brunetti · M. Di Biase

Department of Cardiology, University of Foggia,

“Ospedali Riuniti”OO.RR, viale L Pinto,

1, 71100 Foggia, Italy

e-mail: opsfco@tin.it
} 